\title{
EARLY ESTIMATES OF 2009 PANDEMIC INFLUENZA A(H1N1) VIRUS ACTIVITY IN GENERAL PRACTICE IN FRANCE: INCIDENCE OF INFLUENZA-LIKE ILLNESS AND AGE DISTRIBUTION OF REPORTED CASES
}

\author{
C Turbelin (turbelin@u707.jussieu.fr)1,2, C Pelat ${ }^{1,2}$, P Y Boëlle ${ }^{1,2}$, D Lévy-Bruhl ${ }^{3}$, F Carrat Cat, $^{1,2}$ Blanchon ${ }^{1,2}$, T Hanslik ${ }^{1,4,5}$ \\ 1. Institut national de la santé et de la recherche médicale (INSERM), UMR S 707, F-75012, Paris, France \\ 2. Université Pierre et Marie Curie - Paris 6 (UPMC), Paris, France \\ 3. Institut de Veille Sanitaire (InVS), Saint-Maurice, France \\ 4. Université Versailles Saint Quentin en Yvelines, Versailles, France \\ 5. Assistance Publique Hôpitaux de Paris, Service de Médecine Interne, Hôpital Ambroise Paré, Boulogne Billancourt, France
}

This article was published on 1 October 2009.

Citation style for this article: Turbelin C, Pelat C, Boëlle PY, Lévy-Bruhl D, Carrat F, Blanchon T, Hanslik T. Early estimates of 2009 pandemic influenza A(H1N1) virus activity in general practice in France: incidence of influenza-like illness and age distribution of reported cases. Euro Surveill. 2009;14(39):pij=19341. Available online: http://www. eurosurveillance.org/ViewArticle.aspx?ArticleId=19341

In the end of August 2009, an unusually elevated level of influenzalike illness (ILI) activity was reported to the French Sentinel Network. We quantified the observed excess in ILI cases in France during summer 2009 and characterised age patterns in reported cases. An excess of cases has been observed since 5 July, with a time increasing trend. The cumulated estimated excess number of ILI cases was 269,935 [179,585; 316,512], corresponding to $0.5 \%$ French population over the period. Compared to the same period in the past years, relative cumulated incidence was greater among young subjects and lower among subjects over 65 years-old. Compared to past epidemics, the relative cumulated incidence was greater in children less than five years-old. This excess of cases may reflect the current spread of the $\mathrm{A}(\mathrm{H} 1 \mathrm{~N} 1)$ virus in France, subject to the following limitations: estimates were based on clinical cases consulting a GP; large media coverage may have led to a non specific increase in consultation rates.

\section{Background}

Cases of infection with the 2009 pandemic influenza A(H1N1) virus have been reported in France since May 2009, with first evidence of local secondary transmission in July 2009.

By the end of August, an unusually elevated level of influenzalike illness (ILI) had been reported to the French Sentinel Network (FSN), an epidemiological surveillance system based on general practitioners (GPs) and operating since 1984 in France.

The objective of the present study was to quantify the excess in ILI cases in France during the 2009 summer and to examine age patterns in the reported cases using, for comparison, data reported to a long-running routine surveillance system.

\section{Method}

Sentinel network and estimation of ILI incidence

Sentinel GPs report ILI cases to the FSN in real time. The ILI case definition is sudden onset of fever $\left(39^{\circ} \mathrm{C}\right.$ or above) with myalgia and respiratory signs [1]. Weekly ILI incidence is estimated using the average number of ILI cases reported by GPs, and then extrapolated to national ILI incidence using the ratio of all French GPs to participating sentinel GPs [2]. Characteristics of the GPs in the Sentinel Network are similar to those of all French GPs as regards the regional distribution, the proportion of GPs in rural practice and the type of practice [3].

\section{Expected and excess ILI cases}

Starting on 1 June 2009, the expected ILI incidence was calculated for each week as the average of weekly ILI incidences reported in the preceding, current and following weeks in the period 1985 to 2008 [4]. A 90\% confidence interval was derived from the 5th and 95th percentiles of these values $\left(Q_{5}\right.$ and $Q_{95}$, respectively) for each week.

For a given week, an excess in ILI incidence was defined when the observed incidence was above $Q_{95}$. The number of excess cases was calculated as the difference between the observed and expected incidences. The inferior bound (respectively superior bound) of this excess was calculated as the difference between the observed incidence and $Q_{95}$ (respectively $Q_{5}$ ).

\section{Relative cumulated incidence according to age}

Incidence according to age was determined by apportioning extrapolated cases according to the age distribution in reported cases, using the following age groups: $<5$ years, 5-17, 18-49, $50-64$ and $\geq 65$ years. However, it is difficult to compare directly these incidences with past epidemics as the $A(H 1 N 1)$ pandemic is still in its early phase. Therefore, we extracted the age pattern of reported cases by computing relative incidence rates as the ratio of incidence in an age group to incidence in the whole population. Relative incidences larger than 1 indicate that the corresponding age class experienced larger incidence than the population as a whole.

The relative cumulated incidence rates according to age of ILI cases were calculated for: a) the current period, b) the 
same weeks in the past years and c) the past seasonal epidemic periods, as determined by the FSN and d) the 1986-7 and 1988-9 seasonal epidemics during which influenza $A(H 1 N 1)$ virus was the predominant circulating influenza virus [5].

\section{Results}

As shown in Figure 1, the current estimated ILI incidence has been in excess of expected incidences of ILI cases in France since week 28 of 2009 ( 6 to 12 July), with an increasing time trend.

Weekly estimated excess of ILI cases $(90 \% \mathrm{Cl}$ bounds are presented in brackets) increased from 6,805 [654; 10,076] cases

\section{F I G U R E 1}

Estimated and expected incidence rates and their confidence interval, pandemic influenza $\mathrm{A}(\mathrm{H} 1 \mathrm{~N} 1) 2009$, France

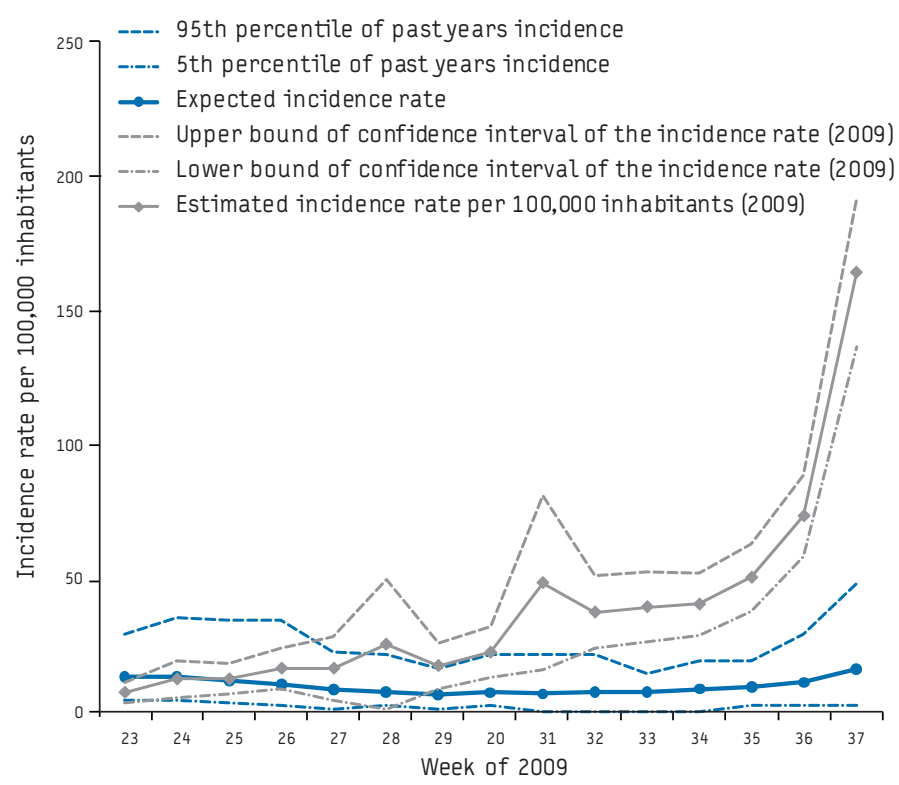

in week 29 , to $92,505[72,563 ; 101,456]$ cases in week 37 , the time of writing this article (Table). Overall, the cumulated excess number of ILI cases between week 28 and week 37 of 2009 was 269,935 [179,585; 316,512] $(323,420$ reported ILI cases minus the expected 53,485 over the period).

The median age of ILI reported cases was 26 years (range: 1-103 years), and $48 \%$ were male. Compared to weeks 28 to 37 of past years since 1985, age group-relative incidence rates of ILI between weeks 28 and 37 of 2009 were greater among subjects less than 18 years-old and smaller in those older than 65 years (Figure 2A).

Compared to past epidemic periods and $\mathrm{A}(\mathrm{H} 1 \mathrm{~N} 1)$ epidemics, age group-relative incidence rates of ILI between weeks 28 and 37 of 2009 was higher among subjects less than 5 years of age and lower among subjects aged 5 to 17 years (Figure 2B).

\section{Discussion}

An excess of 270,000 ILI cases has been reported to the French Sentinel Network since 1 July 2009, with a specific age pattern, compared to cases usually reported at this time of year. Compared to the past seasonal epidemics, (including those with predominant $\mathrm{A}(\mathrm{H} 1 \mathrm{~N} 1)$ circulating), the excess in ILI cases was largest among children less than 5 years-old.

In the past 24 years of surveillance, upper respiratory tract infections have been uncommon in summer, making the last weeks exceptional. Besides the pandemic influenza $A(H 1 N 1)$ virus, no unusual circulation of an infectious agent, nor seasonal influenza viruses have been reported in France since 1 June 2009 [6]. The recent excess of ILI cases must therefore reflect the developing pandemic in France.

Some pitfalls arise in the interpretation of this increasing incidence. First, cases reported by GPs are based on a clinical definition without virological confirmation. This case definition had positive predictive value for approximately $40 \%$ influenza virus infections in the past seasonal epidemics [1]. It has been in use

T A B L E

Estimated and expected number of cases of influenza-like illness and calculated excess of cases in France between week 28 (6 to 12 July) and 37 (7 to 13 September) of 2009

\begin{tabular}{|c|c|c|c|c|c|c|c|}
\hline \multirow[t]{2}{*}{ Week number } & \multirow[t]{2}{*}{ Observed incidence } & \multicolumn{3}{|c|}{ Expected incidence } & \multicolumn{3}{|c|}{ Excess of cases } \\
\hline & & Expected & $\begin{array}{c}5^{\text {th }} \\
\text { percentile }\end{array}$ & $\begin{array}{c}95^{\text {th }} \\
\text { percentile }\end{array}$ & Average & Inferior bound & Superior bound \\
\hline 28 & 15,516 & 4,545 & 1,256 & 13,190 & 10,971 & 2,326 & 14,260 \\
\hline 29 & 10,704 & 3,899 & 628 & 10,050 & 6,805 & 654 & 10,076 \\
\hline 30 & 13,868 & 4,388 & 1,256 & 13,190 & 9,480 & 678 & 12,612 \\
\hline 31 & 30,255 & 4,083 & 0 & 13,190 & 26,172 & 17,065 & 30,255 \\
\hline 32 & 23,151 & 4,493 & 0 & 13,190 & 18,658 & 9,961 & 23,151 \\
\hline 33 & 24,435 & 4,528 & 0 & 8,793 & 19,907 & 15,642 & 24,435 \\
\hline 34 & 24,985 & 5,217 & 0 & 11,934 & 19,768 & 13,051 & 24,985 \\
\hline 35 & 31,660 & 5749 & 1,256 & 11,934 & 25,911 & 19,726 & 30,404 \\
\hline 36 & 46,134 & 6,778 & 1,256 & 18,215 & 39,356 & 27,919 & 44,878 \\
\hline 37 & 102,712 & 9,805 & 1,256 & 30,149 & 92,907 & 72,563 & 101,456 \\
\hline Total & 323,420 & 53,485 & 6,908 & 143,835 & 269,935 & 179,585 & 316,512 \\
\hline
\end{tabular}


for 25 years in the FSN, making it likely that it is currently well applied by GPs. To further improve specificity, we retained only cases in excess of the expected incidence at this time of year in the calculations. Second, the heavy media coverage of the pandemic may have increased the propensity to visit a GP in case of symptoms, leading to an upward bias in the number of excess ILI cases. The change in age pattern of patients consulting their GPs argues against a mere change in consultation frequency; however an age-specific change in propensity to consult may also lead to

\section{F I G U R E 2}

Age group-relative cumulated incidence rates ${ }^{\star}$ of influenza-like illness cases reported by the French Sentinel Network general practitioners between weeks 28 and 37 of 2009 , compared to weeks 28 and 37 of past years since $1985(2 \mathrm{~A})^{*}$ and to past seasonal epidemic periods and past $\mathrm{A}(\mathrm{H} 1 \mathrm{N1})$ epidemics

(1986-7, 1988-9) (2B)
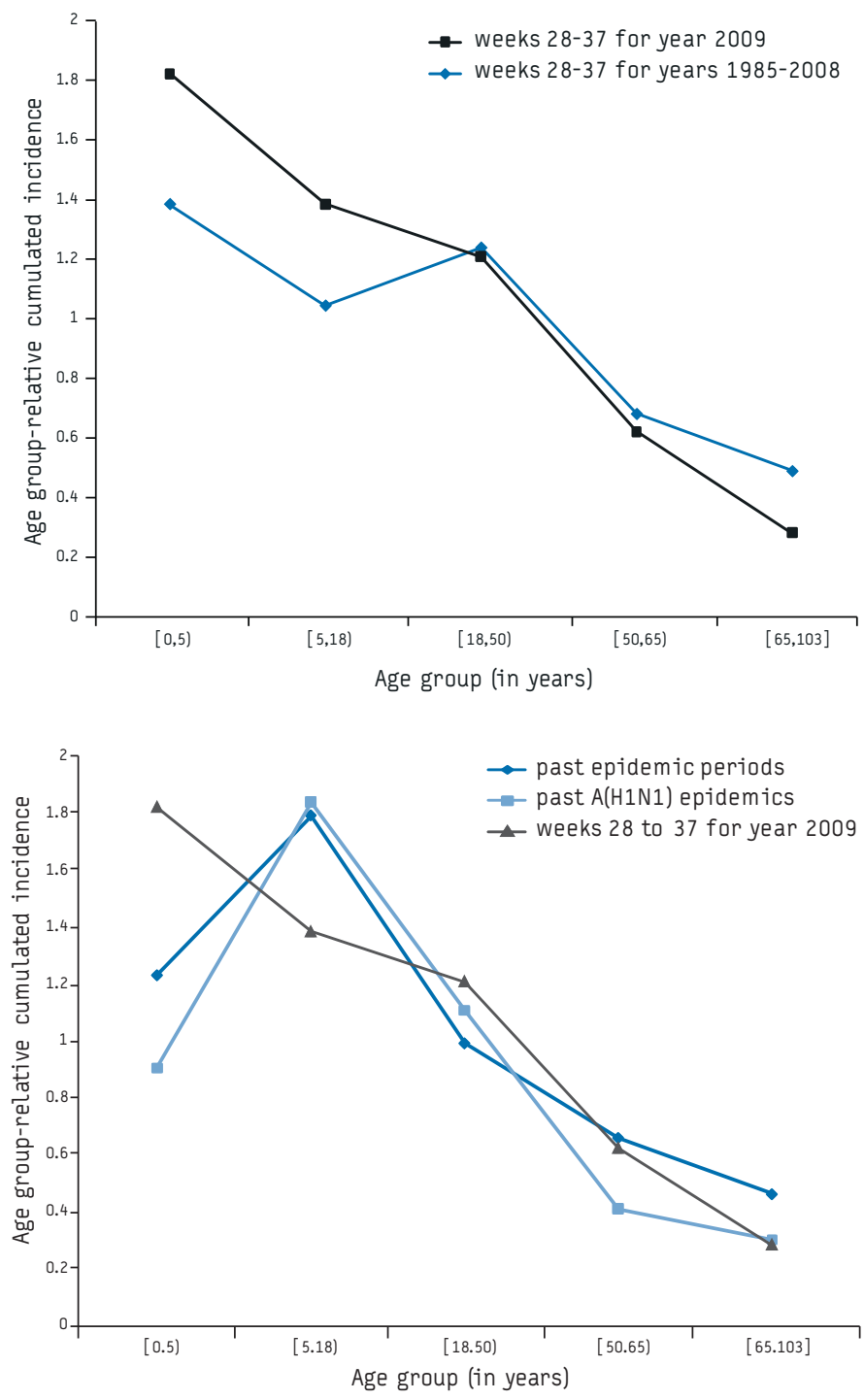

*Ratio of incidence in an age group to incidence in the whole population: relative incidence $>1$ indicates that the corresponding age class experienced larger incidence than the population as a whole. this change. Last, cases of 2009 pandemic influenza $A(H 1 N 1)$ virus infection with mild disease and/or not seeking care are not taken into account in the estimates. We did not change the case definition to include milder cases so that direct comparison with the past years was possible.

As reported in other countries, a relatively higher incidence of 2009 pandemic influenza $A(H 1 N 1)$ virus infection is observed in the young. In most reports, the increased incidence among young subjects could be ascribed to case finding and ascertainment, with more young people being tested, for example as part of outbreaks of influenza in schools [7-9]. Cases seen by the sentinel network GPs may provide a better picture of what is happening in the population at large. Using the same definition as before makes it possible to compare the current situation with the past.

The data confirmed and quantified an epidemic of ILI that started during the recent summer months in France, and had never been observed in the previous 25 years, with an age-specific incidence different from previous epidemic periods. These preliminary data highlight the heavy burden of this ILI epidemic on small children, relatively to older persons [10].

\section{Acknowledgements}

We want to thank all general practitioners of the French Sentinel Network.

* Authors correction

The legend of Figure $2 \mathrm{~A}$ was corrected after the publication of the article, on 6 October 2009.

\section{References}

1. Carrat F, Tachet A, Rouzioux C, Housset B, Valleron AJ. Evaluation of clinical case definitions of influenza: detailed investigation of patients during the 1995-1996 epidemic in France. Clin Infect Dis. 1999;28(2):283-90.

2. Garnerin P, Saidi Y, Valleron AJ. The French Communicable Diseases Computer Network. A seven-year experiment. Ann N Y Acad Sci. 1992;670:29-42.

3. Chauvin P, Valleron AJ. Attitude of French general practitioners to the public health surveillance of communicable diseases. Int J Epidemiol. 1995;24(2):43540.

4. Stroup DF, Williamson GD, Herndon JL, Karon JM. Detection of aberrations in the occurrence of notifiable diseases surveillance data. Stat Med. 1989;8(3):323-9; discussion 31-2.

5. Denoeud L, Turbelin C, Ansart S, Valleron AJ, Flahault A, Carrat F. Predicting pneumonia and influenza mortality from morbidity data. PLoS One. 2007;2(5):e464.

6. Institut de veille sanitaire (InVS). Bulletin grippe A (H1N1) 2009, situation au 21 juillet 2009 [influenza A(H1N1) 2009 epidemiological report, situation as of 21 July 2009]. Bulletin grippe A (H1N1) 2009 [serial on the Internet]. 2009. French. Available from: http://www.invs.sante.fr/surveillance/grippe_dossier/ points_h1n1/grippe_A_h1n1_220709/Bulletin_grippe_22_07_09.pdf

7. Baker MG, Wilson N, Huang QS, Paine S, Lopez L, Bandaranayake D, et al. Pandemic influenza $A(\mathrm{H} 1 \mathrm{~N} 1) \mathrm{v}$ in New Zealand: the experience from April to August 2009. Euro Surveill. 2009;14(34):pii=19319. Available from: http://www. eurosurveillance.org/ViewArticle.aspx?ArticleId=19319

8. Dawood FS, Jain S, Finelli L, Shaw MW, Lindstrom S, Garten RJ, et al. Emergence of a novel swine-origin influenza A (H1N1) virus in humans. N Engl J Med. 2009;360(25):2605-15.

9. Gilsdorf A, Poggensee $G$, on behalf of the working group pandemic influenza $A(H 1 N 1) v$. Influenza A(H1N1)v in Germany: the first 10,000 cases. Euro Surveill. 2009;14(34):pij=19318. Available from: http://www.eurosurveillance.org/ ViewArticle.aspx?ArticleId $=19318$

10. Centers for Disease Control and Prevention (CDC). Surveillance for pediatric deaths associated with 2009 pandemic influenza A (H1N1) virus infection - United States, April-August 2009. MMWR Morb Mortal Wkly Rep. 2009;58(34):941-7. 